2 Structural characterization of lactone-containing MW 212 organosulfates originating from

3 isoprene oxidation in ambient fine aerosol

4 Paulina Wach ${ }^{1), 2)^{*}, \text { Grzegorz Spólnik }^{2)} \text {, Jason D. Surratt }}{ }^{5)}$, Kacper Blaziak ${ }^{6)}$, Krzysztof J.

$5 \quad$ Rudzinski ${ }^{1)}$, Ying-Hsuan Lin ${ }^{7)}$, Willy Maenhaut ${ }^{4)}$, Witold Danikiewicz ${ }^{2)}$, Magda Claeys ${ }^{3)}$, and

6 Rafal Szmigielski ${ }^{1}{ }^{*}$

7 1)Institute of Physical Chemistry, Polish Academy of Sciences, 01-224 Warsaw, Poland

8 2)Institute of Organic Chemistry, Polish Academy of Sciences, 01-224 Warsaw, Poland

9 3)Department of Pharmaceutical Sciences, University of Antwerp, BE 2610 Antwerp, Belgium

10 4)Department of Chemistry, Ghent University, BE 9000 Ghent, Belgium

11 5)Department of Environmental Sciences and Engineering, Gillings School of Global Public

12 Health, University of North Carolina at Chapel Hill, Chapel Hill, NC 27599, USA

$13{ }^{6)}$ Faculty of Chemistry, University of Warsaw, Pasteura 1, 02-093 Warsaw, Poland

$14{ }^{7)}$ Department of Environmental Sciences, University of California, Riverside, CA 92521, USA

$15 *$ Corresponding authors:

16 Phone: +48 (22) 343 3402, e-mail: ralf@ichf.edu.pl paulina.wach@ichf.edu.pl 


\begin{tabular}{|c|c|c|c|c|}
\hline Sample type & \begin{tabular}{|l|} 
Peak \\
no.
\end{tabular} & $\begin{array}{l}\text { Retention time } \\
\text { (min) }\end{array}$ & $\begin{array}{l}\text { Peak area } \\
(\%)^{\mathrm{a}}\end{array}$ & $\begin{array}{l}\Sigma(m / z, 211) / \Sigma(m / z \\
215)^{\mathrm{b}}\end{array}$ \\
\hline$K$-puszta $\mathrm{PM}_{2.5}$ & $\begin{array}{l}1 \\
2 \\
3 \\
4\end{array}$ & $\begin{array}{l}1.05 \\
1.29 \\
1.42 \\
1.53\end{array}$ & $\begin{array}{l}18.34 \\
37.06 \\
24.27 \\
20.33\end{array}$ & 1.3 \\
\hline Diabla Gora $\mathrm{PM}_{10}$ & $\begin{array}{l}1 \\
2 \\
3 \\
4\end{array}$ & $\begin{array}{l}1.08 \\
1.31 \\
1.46 \\
1.57\end{array}$ & $\begin{array}{l}28.25 \\
37.67 \\
22.95 \\
11.13\end{array}$ & 0.47 \\
\hline Centreville $\mathrm{PM}_{2.5}$ & $\begin{array}{l}1 \\
2 \\
3 \\
4\end{array}$ & $\begin{array}{l}1.03 \\
1.27 \\
1.43 \\
1.53\end{array}$ & $\begin{array}{l}37.68 \\
3.18 \\
17.19 \\
13.35\end{array}$ & 0.19 \\
\hline $\begin{array}{l}\text { Aqueous-phase isoprene } \\
\text { SOA }\end{array}$ & $\begin{array}{l}1 \\
2 \\
3^{c}\end{array}$ & $\begin{array}{l}1.03 \\
1.28 \\
1.41\end{array}$ & $\begin{array}{l}4.81 \\
49.24 \\
45.95\end{array}$ & 3.70 \\
\hline $\begin{array}{l}\text { Smog chamber isoprene } \\
\text { SOA }\end{array}$ & \begin{tabular}{|l}
1 \\
2 \\
3 \\
4
\end{tabular} & $\begin{array}{l}1.06 \\
1.30 \\
1.41 \\
1.55\end{array}$ & $\begin{array}{l}47.21 \\
23.47 \\
23.59 \\
5.74\end{array}$ & 0.05 \\
\hline
\end{tabular}

19

20 a the relative composition in percentage of the total peak areas in the $m / z 211$ extracted ion

21 chromatograms (EICs). 
$22 \mathrm{~b}$ the ratios were determined from the $m / z 211$ and $m / z 215$ EICs (Fig. S1).

$23{ }^{\mathrm{c}}$ Peaks $3^{\text {rd }}$ and $4^{\text {th }}$ were integrated together due to the low peak resolution.

24 Table S1. Comparison of the main peaks areas for $m / z 211\left([\mathrm{M}-\mathrm{H}]^{-}\right.$elemental composition:

$25 \mathrm{C}_{5} \mathrm{H}_{7} \mathrm{SO}_{7}$; the exact mass measurements for all peaks were performed within $3 \mathrm{mDa}$ mass error)

26 present in the ambient fine aerosol samples ( $K$-puszta, Hungary; Diabla Gora, Poland;

27 Centreville, USA), aqueous-phase isoprene SOA, and smog-chamber isoprene SOA, and ratios

28 between the sum of the $m / z 211$ peak areas versus that of the $m / z 2152$-methyltetrol sulfates. 


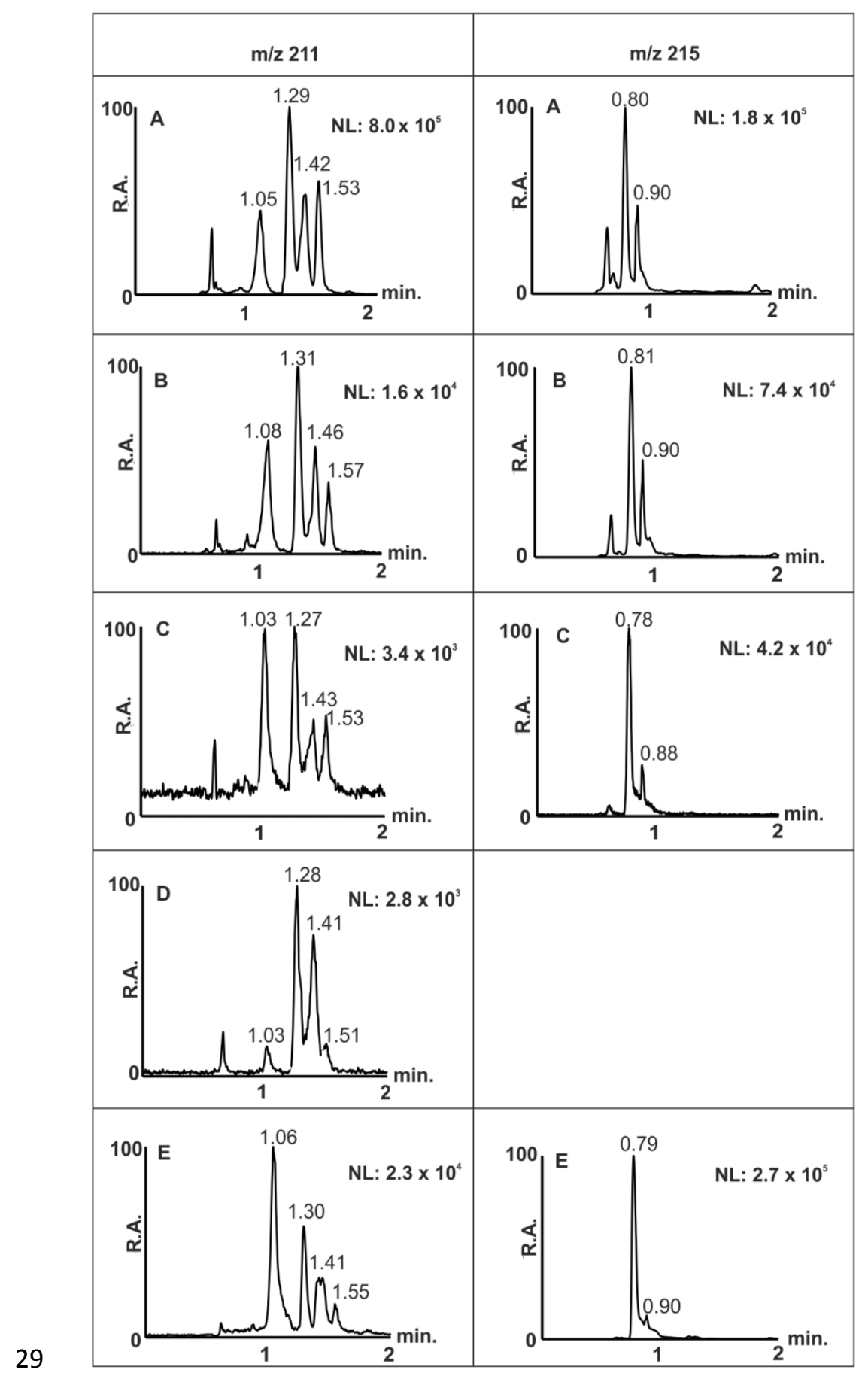

30 Figure S1. Comparison of extracted ion chromatograms of examined $\mathrm{m} / \mathrm{z} 211$ and isoprene SOA

31 marker the 2-methyltetrol sulfate ion $\mathrm{m} / \mathrm{z} 215$ in selected ambient, aqueous-phase and smog

32 chamber samples: (A) K-puszta $\mathrm{PM}_{2.5}$ aerosol (B) Diabla Gora $\mathrm{PM}_{2.5}$ aerosol (C) Centreville 
$33 \mathrm{PM}_{2.5}$ aerosol (D) aqueous-phase isoprene SOA (E) smog chamber isoprene SOA. Abbreviation:

34 NL, normalization level.

35

36

1)
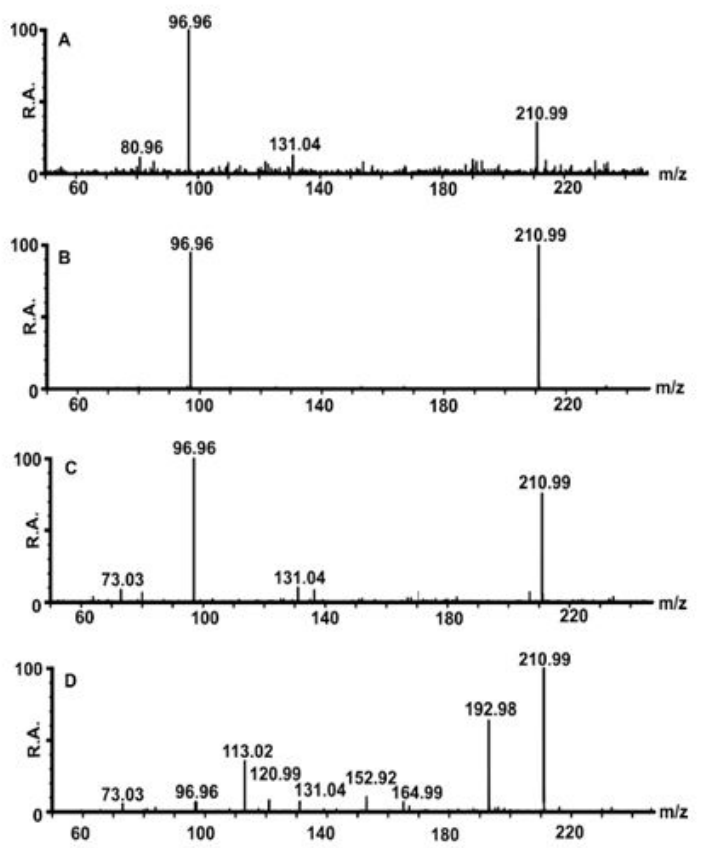

2)
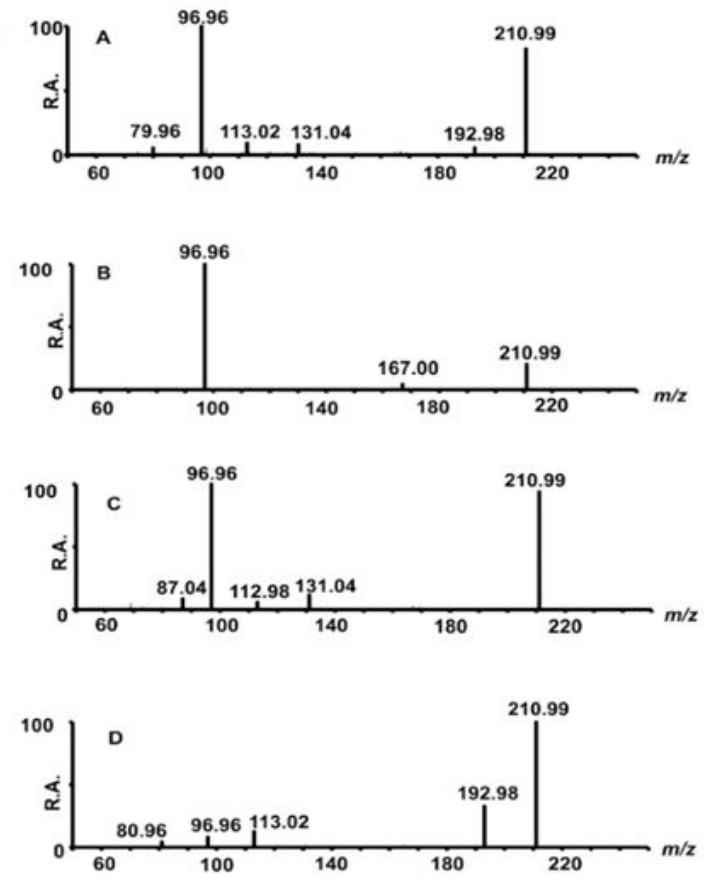

37

38 Figure S2. Second-order spectra of the $m / z 211$ ion for:

39 1) aqueous-phase isoprene SOA: peaks with retention times at (A) 1.03 min. (B) 1.28 min (C)

$40 \quad 1.41 \mathrm{~min}$ and (D) $1.51 \mathrm{~min}$ and 2) smog chamber isoprene SOA: peaks with retention times at (A)

$41 \quad 1.06 \mathrm{~min}(\mathrm{~B}) 1.30 \mathrm{~min}(\mathrm{C}) 1.43 \mathrm{~min}$ and (D) $1.55 \mathrm{~min}$. 

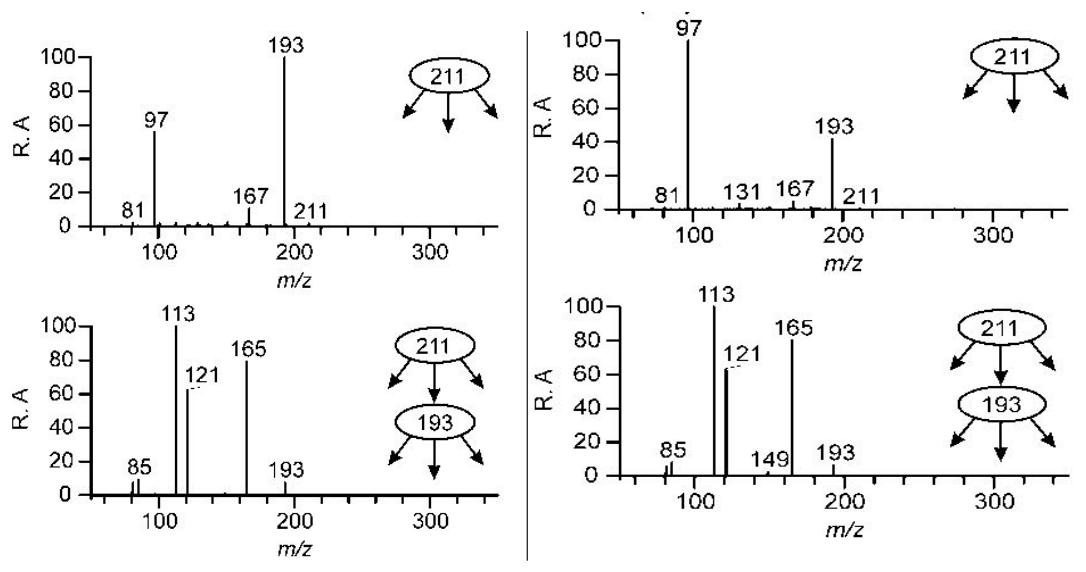

43

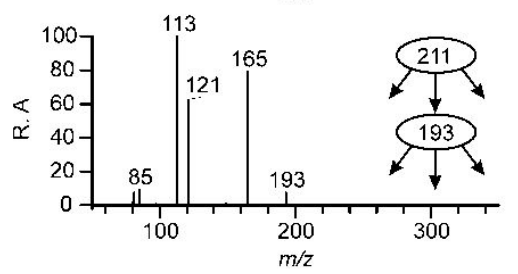

48 Figure S3. Ion trap $\mathrm{LC}_{\mathrm{MS}} \mathrm{MS}^{2}$ and $\mathrm{MS}^{3}$ product ion spectra of $m / z 211$ obtained for the first- (RT

$491.05 \mathrm{~min}$; left panel) and last-eluting (RT $1.53 \mathrm{~min}$; right panel) MW 212 OSs from K-puszta

$50 \quad \mathrm{PM}_{2.5}$ aerosol (Fig. 1A). The data show that fragmentation of $\mathrm{m} / \mathrm{z} 211$ mainly gives rise to loss of

51 water $(\mathrm{m} / \mathrm{z} 193)$ and the sulfate ion $(\mathrm{m} / \mathrm{z} 97)$, while further fragmentation of $\mathrm{m} / \mathrm{z} 193$ results in the

52 loss of $\mathrm{CO}(\mathrm{m} / \mathrm{z} 165)$ and the ions at $\mathrm{m} / \mathrm{z} 121$ and 113 . The experimental conditions for the ion

53 trap MS data are given in Gómez-González et al. ${ }^{1}$ 

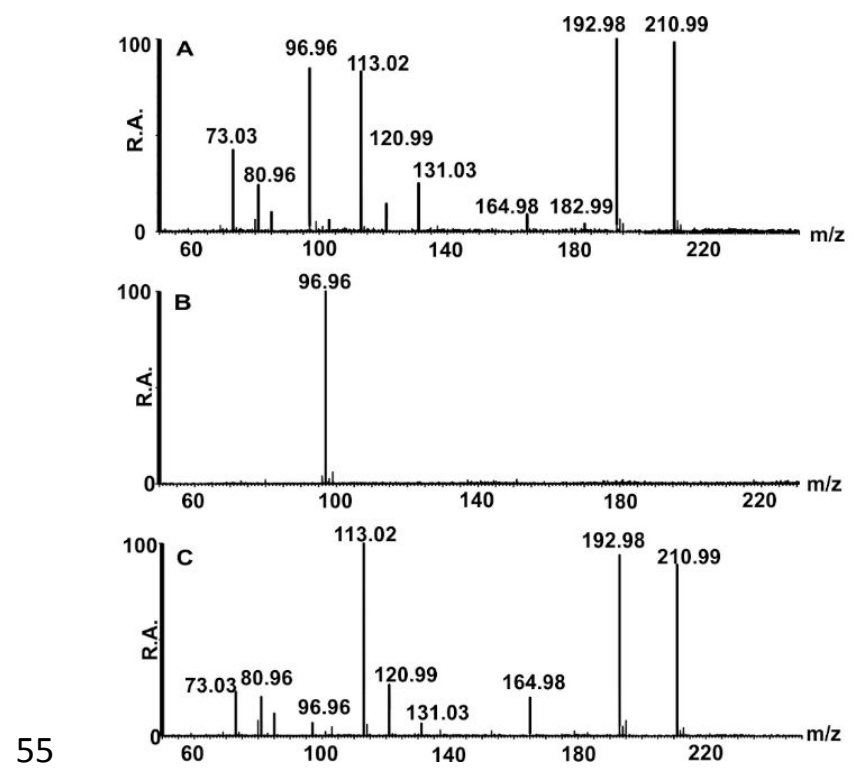

56 Figure S4. $\mathrm{MS}^{2}$ data for 4-methyl-2(5H)-furanone SOA for peaks with retention times at (A)

$57 \quad 1.07 \mathrm{~min}(\mathrm{~B}) 1.31 \mathrm{~min}$ and (C) $1.57 \mathrm{~min}$.

58
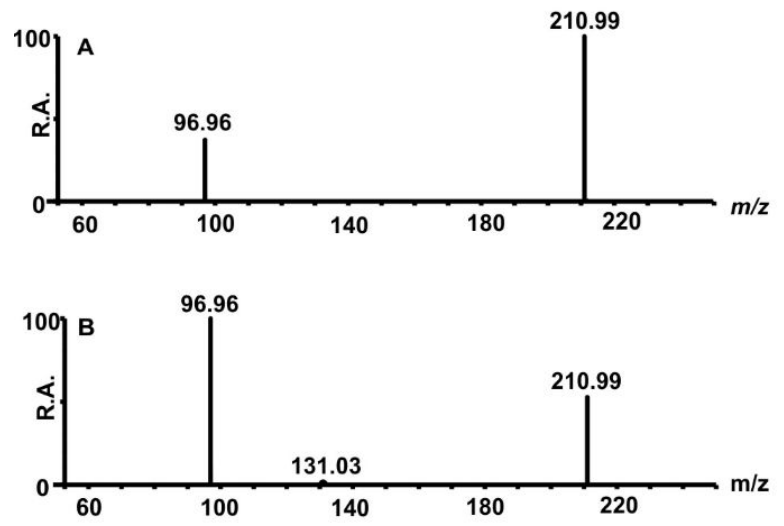

59

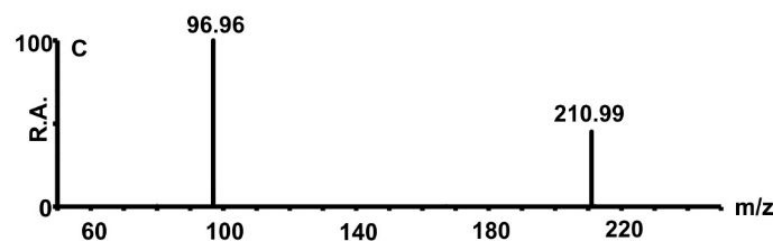


60 Figure S5. $\mathrm{MS}^{2}$ data for 3-methyl-2(5H)-furanone SOA for peaks with retention times at (A)

$611.33 \mathrm{~min}(\mathrm{~B}) 1.42 \mathrm{~min}$ and (C) $1.44 \mathrm{~min}$.

62

63 Theoretical Calculations

64 Quantum chemical calculations were performed to obtain insight into two major fragmentation 65 pathways, observed in the $m / z 211 \mathrm{MS}^{2}$ spectra (Fig. 3), i.e.:

(1) a loss of water leading to the formation of the $m / z 193$ ion,

67

(2) a formation of the bisulfate ion $(m / z 97)$.

68 It is noted that these two fragmentation pathways are also observed in the $m / z 211 \mathrm{MS}^{2}$ ion trap

69 spectra obtained for the first- and last-eluting chromatographic peak from $K$-puszta $\mathrm{PM}_{2.5}$ sample

70 (Fig. 1A; Fig. 2S). The computed reaction activation barriers, corresponding to the transition state

71 electron energies are presented in Scheme SI. 



73 Scheme S1. Calculated activation energy barriers of the eight diasteroisomers for the water

74 elimination reaction and sulfate ion formation. The transition state electron energies and the ZPE

75 correction were calculated at B3LYP/6-311+g(2d,p) level of theory. The lowest energy values are

76 highlighted in green color. 
78 For the stereoisomer that can be equally assigned to structure (A), one fragmentation channel

79 leading to the loss of water and three reaction pathways for $\mathrm{HSO}_{4}{ }^{-}$ion formation were found.

80 The most kinetically preferred reaction with an energy barrier of $167 \mathrm{~kJ} / \mathrm{mol}$ is the neutral loss of

$81114 \mathrm{Da}$, leading to the formation of the bisulfate ion $(\mathrm{m} / z$ 97). The alternative reaction, where a

82 molecule of water is detached from the molecule is clearly kinetically less favorable with a higher

83 activation barrier of $259 \mathrm{~kJ} / \mathrm{mol}$. The difference between transition state energies of the main

84 fragmentation channels suggests that bisulfate ion $(\mathrm{m} / \mathrm{z} 97)$ formation should be the most

85 dominant or even the only observed fragmentation process. The same conclusion can be drawn

86 for the enantiomer (B) where the hydroxyl and sulfate groups are located in a trans manner.

87 However, here only three fragmentation channels were found, one for water loss and two for

88 sulfate ion formation. The trans orientation of the key functional groups $\left(-\mathrm{OH}\right.$ and $\left.-\mathrm{SO}_{4}^{-}\right)$cause a

89 significant steric hindrance, which makes the appropriate epoxide formation impossible.

90 In structure (C) the hydroxyl group is located at C- 3 and the sulfate ligand is bonded at C-4. For

91 these molecules four transformation pathways were found, two for the water elimination reaction

92 and two for bisulfate ion formation. The most kinetically preferred reaction channel leads to the

93 formation of the $\mathrm{HSO}_{4}^{-}$ion and a neutral epoxide species with an activation energy barrier of 228

$94 \mathrm{~kJ} / \mathrm{mol}$. The alternative water elimination reaction requires a higher energy input of $245 \mathrm{~kJ} / \mathrm{mol}$.

95 The same reactivity can be observed for enantiomer(D), but here due to the trans steric effect,

96 that was discussed earlier, bisulfate ion formation leads to a different neutral lactone-containing

97 product (Scheme S1).

98 Theoretical investigations of the reaction kinetic properties of the sulfate esters of 3,4-dihydroxy-

99 3-methyl-tetrahydro-2-furanone steroizomers (A) - (D), show that in all the cases the $m / z 211$

100 precursor ions most likely undergo the fragmentation reactions leading to the formation of the 
101 bisulfate ion $(\mathrm{m} / \mathrm{z}$ 97) upon CID. This observation seems to be in a good agreement with the 102 experimental fragmentation patterns (Fig. S3) recorded for chromatographic peaks (1,2 and 6) 103 shown in Figure 4, where the $\mathrm{HSO}_{4}{ }^{-}$ion is the only product ion.

104 In the second part of the study, the appropriate activation energy barriers were calculated for the 105 set of the steroisomers (E-H) of sulfate esters of 3,4-dihydroxy-4-methyl-tetrahydro-2-furanone.

106 For the first twosteroisomers, $(\mathrm{E})$ and $(\mathrm{F})$ the reaction pathway leading to the loss of water was 107 not found. All attempts to simulate the mechanism where the proton located on C-3 is transferred 108 to the hydroxyl group, results in a simultaneous second proton transfer from the oxygen to the $109 \mathrm{OSO}_{3}{ }^{-}$moiety, leading to immediate elimination of the bisulfate ion. In this respect, the only 110 fragmentation pathway that was found for (I-F) ions is the neutral loss of $114 \mathrm{Da}$. Additionally, it 111 has to be noted that during the bisulfate ion formation process different neutral lactone-containing 112 molecules are formed from each stereoisomer (Scheme S1).

113 Stereoisomer $(\mathrm{G})$ can undergo four fragmentation reactions, three of them lead to the loss of 114 water, while the fourth one results in the formation of the sulfate ion and an epoxide-type of 115 neutral species. The calculated transition state energy values show that there is a clear direct 116 competition between the two main dissociation channels. The lowest calculated activation energy 117 for the water loss reaction is of $254 \mathrm{~kJ} / \mathrm{mol}$, while the alternative $\mathrm{HSO}_{4}{ }^{-}$ion formation pathway 118 requires just a slightly higher energy of $263 \mathrm{~kJ} / \mathrm{mol}$. The relatively small energy difference might 119 suggest, that both processes seem to be almost equally preferred and may occur at the same time 120 with comparable efficiency.

121 In last steroisomer $(\mathrm{H})$ the ester $\left(-\mathrm{OSO}_{3}{ }^{-}\right)$and the hydroxyl groups are trans-located, which 122 makes the appropriate epoxide formation and sulfate ion elimination sterically not available. 
123 Thus, the only identified dissociation channel for these molecules, lead to water elimination via 124 the lowest energy barrier of $237 \mathrm{~kJ} / \mathrm{mol}$.

125

\section{Alternative mechanism}

127 The alternative mechanism of the formation of MW 212 organosulfates in the aqueous solution is 128 possible, especially when isoprene is exposed to sulfate radicals at high concentrations, e.g., 129 effectively produced during autoxidation of S(IV) ${ }^{2,3}$ The mechanism leads to the formation of at 130 least 12 isomers of MW 212, 8 isomers of MW 214 and 4 isomers of MW 210. Scheme S4 shows 131 the principle of this approach. 

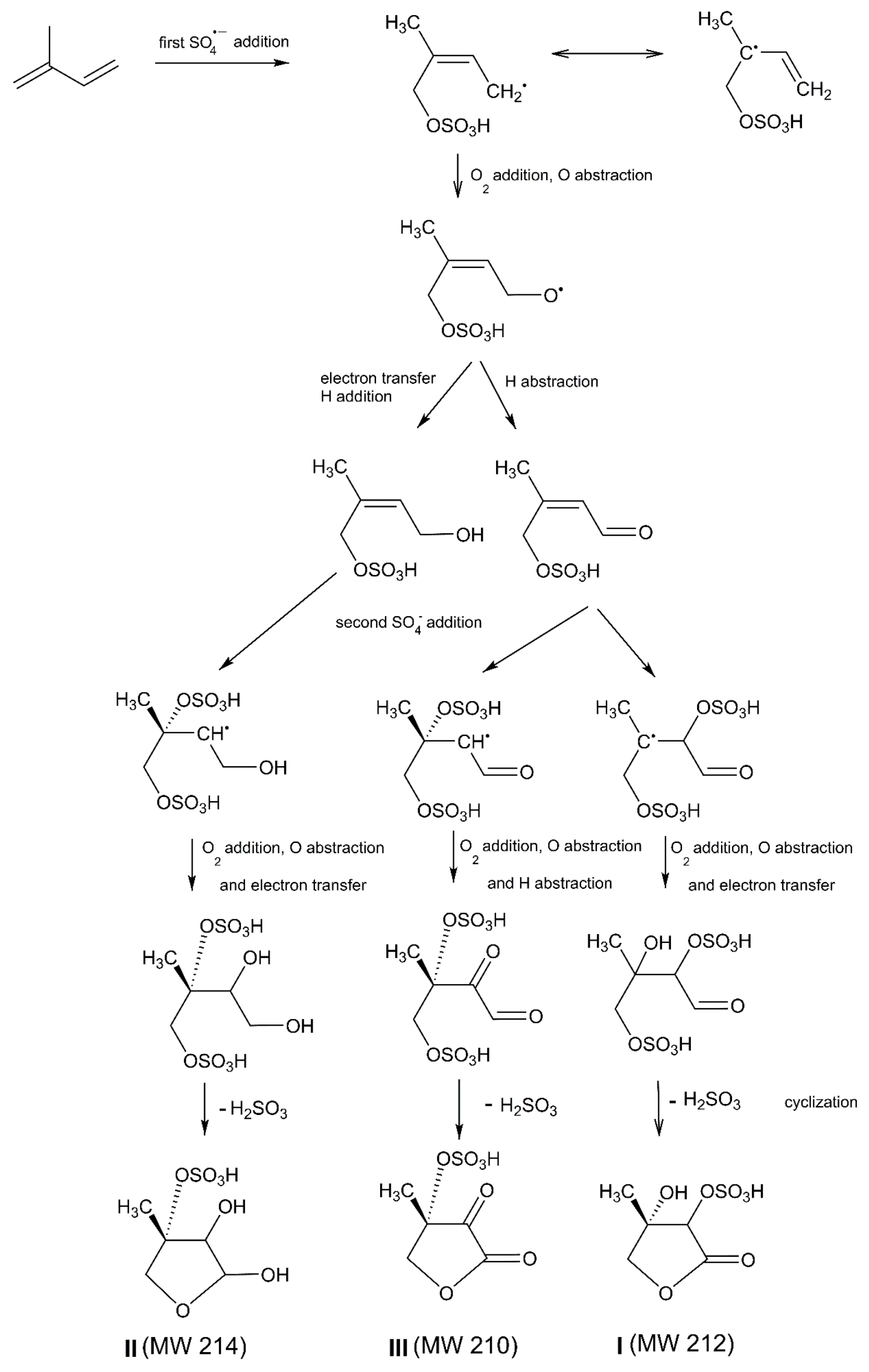
133 Scheme S2. The plausible formation mechanism of the MW 212 OS from isoprene in the 134 aqueous solution during the S(IV)-autooxidation. A key step in this approach is an addition of 135 the sulfate radical anion onto the $\mathrm{C}=\mathrm{C}$ bond.

136 The mechanism starts with the addition of a sulfate radical to one of the double bonds in an 137 isoprene molecule that results in formation of an alkene radical. Then, an oxygen molecule adds 138 to the radical and a peroxy radical is formed. In the next step, another reactant, e.g. a $\mathrm{HSO}_{3}{ }^{-}$ion, 139 abstracts a terminal oxygen atom from the radical to form $\mathrm{HSO}_{4}{ }^{-}$and an alkoxy radical. The 140 alkoxy radical can take two reaction pathways - (i) electron transfer to another reactant, e.g. a $141 \mathrm{SO}_{3}{ }^{2-}$, and eventual protonation, or (ii) hydrogen abstraction, if available at the radical $\mathrm{C}$ atom, by 142 another reactant, e.g. $\mathrm{O}_{2}$. In the first case, a hydroxyl alkene sulfate is formed while in the second 143 case the product is a carbonyl alkene sulfate. In both cases, a companion product is a radical that 144 facilitates further chain reactions: $\mathrm{SO}_{3}{ }^{-}$and $\mathrm{HO}_{2}$, respectively. Each alkene sulfate formed has a 145 double $\mathrm{C}=\mathrm{C}$ bond to which another sulfate radical can add (second addition). Then, all the 146 reactions that followed the first addition of sulfate radical can take place. In each case, the 147 reaction sequence ends with formation of a methyl alkane disulfate that can undergo a 148 spontaneous cyclization to a lactone sulfate, with $\mathrm{H}_{2} \mathrm{SO}_{3}\left(\mathrm{H}_{2} \mathrm{O}\right.$ and $\left.\mathrm{SO}_{2}\right)$ as a leaving moiety. If 149 the first and second series of reactions include one electron transfer step and one hydrogen 150 abstraction step, a methyl lactone sulfate (I) formed contains one hydroxyl and one carbonyl 151 group (MW 212). If the two series include two electron transfer steps, the product (II) contains 152 two hydroxyl groups (MW 214). If the series include two hydrogen abstractions, the product (III) 153 contains two carbonyl groups (MW 210). Mechanism intermediates, namely the hydroxyl alkene 154 sulfates and carbonyl alkene sulfates were identified in earlier experiments on isoprene 155 transformation coupled with autoxidation od S(IV). ${ }^{3}$ 


\section{References}

157 1. Gómez-González, Y., Surratt, J. D., Cuyckens, F., Szmigielski, R., Vermeylen, R., Jaoui, 158 M., Lewandowski, M., Offenberg, J. H., Kleindienst, T. E., Edney, E. O., Blockhuys, F., Van 159 Alsenoy, C., Maenhaut, W., and Claeys, M.: Characterization of organosulfates from the 160 photooxidation of isoprene and unsaturated fatty acids in ambient aerosol using liquid 161 chromatography/(-)electrospray ionization mass spectrometry, J. Mass Spectrom. 2008, 43, $162 \quad 371-382$.

163 2. Rudzinski, K. J.; Gmachowski, L.; Kuznietsova, I., Reactions of isoprene and sulphoxy 164 radical-anions - a possible source of atmospheric organosulphites and organosulphates. Atmos 165 Phys Chem 2009, 9(6), 2129-2140.

166 3. Rudzinski, K. J., Degradation of isoprene in the presence of sulphoxy radical anions. J. 167 Atmos. Chem. 2004, 48, 191-216. 